\title{
APUNTES PARA UNA CRONOLOGÍA DEL CINE DOMINICANO
}

\author{
Notes for a chronology of dominican cinema
}

\section{Gerardo Roa Ogando ${ }^{1}$}

DOI: http://dx.doi.org/10.22206/cys.2017.v42i4.pp85-90

Las primeras actividades relacionadas con el séptimo arte en la República Dominicana, iniciaron en agosto de 1900 en el teatro puertoplateńo de Jorge Curiel. En aquel entonces tuvo lugar la presentación del cinematógrafo de los hermanos Lumiere, Louis y Auguste, a cargo del empresario Francesco Grecco, promotor del incipiente artefacto cultural por la región del Caribe, a solo cinco años de su invención en París. Según Sáez (1982, p. 10) "un buen día de agosto de 1900 llegó el juguete de los Lumiere a Puerto Plata, y sin quererlo nos incorporamos a la historia del cine" (...).

Aquella primera muestra de cine en territorio nacional coincidió con los principales descubrimientos tecnológicos y científicos que se estaban gestando en el mundo. Fue el período en que Guillermo Marconi inventó la radio, Antonine Lavoisier descubrió la ley de la conservación de la materia, Albert Einstein formuló su famosa ecuación que le permitió explicar con mayor objetividad la ley de la conservación de la energía. En el campo de la medicina, el patólogo y biólogo austríaco, Karl Landsteiner, descubrió la tipificación sanguínea, etc. Por lo tanto, ese período anterior a la Primera

\footnotetext{
1. Profesor investigador de la Universidad Autónoma de Santo Domingo (UASD). E-mail: gerardoroaogando@gmail.com
}

Guerra Mundial se convirtió en el momento más oportuno para que Alice Guy, mujer de un pensamiento trascendente, introdujera temas e ideologías a la narrativa cinematográfica. En definitiva,

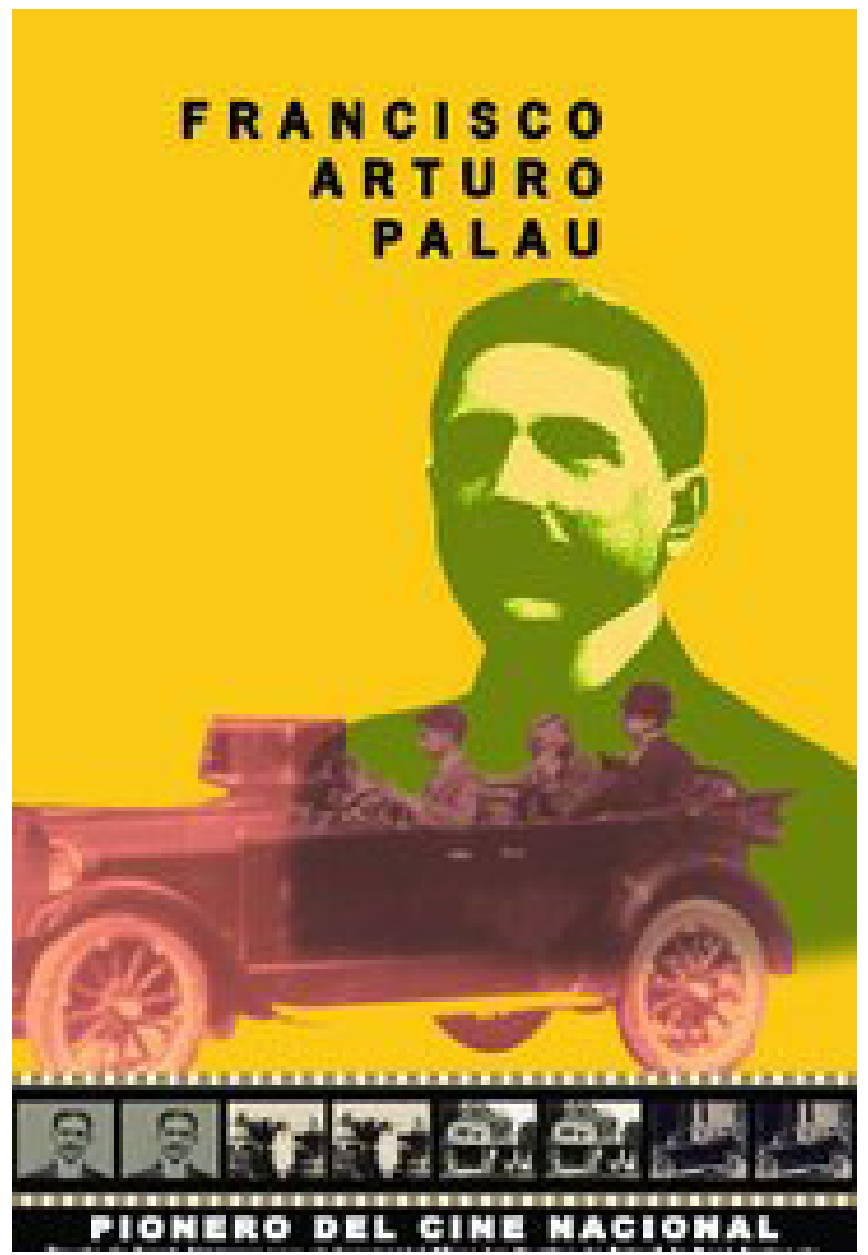


era la Belle Époque, allende los mares (Rudorff, 1973).

En Santo Domingo, el ámbito cultural estaba gestando su propio desarrollo a través de las producciones literarias. Justo en el mismo año en que llegó el cinematógrafo al país, Otilio Vigil Díaz fundó el Vedrinismo ${ }^{2}$, mientras para el 15 de julio de 1912 el presidente Eladio Victoria promulgó una ley que declaraba el castellano como lengua oficial del país.

Todos estos acontecimientos tuvieron lugar en un período en el que la demografía de la ciudad de Santo Domingo era muy precaria. Para ese entonces el medio de transporte por excelencia eran los caballos. Aunque había dos carros de transporte para toda la zona urbana, el mal estado de las calles no entusiasmaba a la población con este avanzado medio de locomoción que había conocido a través de las primeras películas francesas, italianas y norteamericanas.

En este contexto nacional e internacional tuvo lugar la segunda muestra cinematográfica dominicana, cuando el puertorriqueño Rafael Colorado produjo: Excursión de José de Diego en Santo Domingo, (1915) siendo la primera película extranjera filmada en territorio dominicano, un año antes de la primera ocupación estadounidense. Pero fue en los primeros años del siglo xx cuando inició lo que el cineasta y cronista dominicano Félix Manuel Lora Robles denomina "prehistoria fílmica del cine dominicano" (Lora, 2013, p. 357). Se refiere a la producción y estreno, en 1922 y 1923 respectivamente, de Leyenda de Nuestra Señora de Altagracia, conato producido por los fotógrafos Francisco Palau, Tuto Báez y Juan B. Alfonseca, quienes un año después también

2. El Vedrinismo fue el primer movimiento de vanguardia literaria netamente dominicano, creado por Otilio Vigil Díaz en el año 1900, y continuado por Zacarías Espinal. Su principal característica fue la ruptura con la métrica tradicional del medioevo europeo y la introducción del verso libre a la poética dominicana. estrenaron el segundo filme romántico: Las emboscadas de cupido (Cruz, 2011).

Estas pinceladas también coincidieron con grandes acontecimientos del mundo, como la rápida proliferación de las emisoras radiales y la difusión de las primeras señales televisivas. Igualmente concordaron con los últimos años de la primera intervención norteamericana a la República Dominicana. El panorama planetario estaba matizado por las secuelas de la Primera Guerra Mundial y por el de la llamada epidemia de influenza espańola; mientras que en Estados Unidos algunas decisiones económicas fallidas produjeron la mayor crisis del siglo xx, también conocida como la Gran Depresión.

Tal vez no sea posible establecer con certeza el grado en que estos acontecimientos favorecieron el incipiente nacimiento del cine nacional. Pero tampoco puede negarse que dichos eventos sirvieron de insumo al desarrollo del cine mundial, mientras el cine dominicano continuaba siendo un pequeño embrión centrado, en principios, en temáticas alusivas a la superstición y a las historias románticas, aunque con una tendencia a la imitación de los filmes extranjeros que se exhibían en los teatros del país.

A partir de la década de 1930, el panorama socio-político restringió la creación cinematográfica. En ese mismo ańo, en la inauguración del régimen del dictador Rafael Leónidas Trujillo, fue presentada la primera película con sonidos e imágenes. Sin embargo, la dictadura frenó la libre difusión del pensamiento a través del cine, por lo que los pocos documentales registrados estaban orientados a resaltar las bondades del régimen y las películas extranjeras eran clasificadas por colores, que indicaban cuáles eran aptas para determinado público y cuáles estaban tajantemente prohibidas (Sáez, 1982).

El segundo hallazgo cinematográfico correspondiente a la dictadura tuvo lugar entre los años 1955 a 1960, cuando Oscar Torres presentó la siguiente serie de películas: Nenén de la Ruta Mora; ¿Qué 
opina la mujer?; Olas y Arenas; El yugo; La Ronda incompleta y Tierra olvidada.

Algunos cronistas consultados han sido enfáticos al afirmar que las películas extranjeras, permitidas en las salas de cine dominicano para la época del déspota, eran solo aquellas que no despertaban el espíritu de sublevación. Por ejemplo, Sosa $(2017$, p. 1) dice que "durante la dictadura de Rafael Leónidas Trujillo (1930-1961) el cine dominicano fue despojado de iniciativas y creatividad para pasar a ser un instrumento de propaganda (...) Trujillo (...) adoptó este arte "como instrumento ideológico" con la elaboración exclusiva de trabajos documentales referentes al tirano y a sus allegados". Otro ejemplo lo constituye el referido por Carrasco (2013, p. 2) quien reitera que para la época del tirano "había un lavado de cerebro colectivo, menos en aquellas personas más cultivadas y con más sentido patriótico que sabían realmente lo que estaba pasando en el país".

Para el año 1951, Trujillo promulgó la ley 1951 del 7 de marzo de 1949, prohibiendo la proyección de películas en las cuales trabajasen artistas reconocidos como comunistas o como promotores de esa ideología (Báez, 2017). Por eso, los trece documentales producidos por Rafael Augusto Sánchez Sanlley, con el patrocinio de la empresa Cine Dominicano, respondieron a los intereses del tirano.

La primera película estrenada en tierra dominicana, posterior a la muerte de Trujillo, lleva por título: 30 de mayo: gesta libertadora, dirigida por Hugo Mateo (Lora, 2005). En 1963 Franklin Domínguez presentó el largometraje La silla, en la que transmite temas que denuncian las atrocidades de la dictadura. Cuatro años más tarde, en 1967, los cineastas Max Pou y Eduardo Palmer presentaron los documentales: El esfuerzo de un pueblo y Nuestra Historia (Frías, 1985).

En 1965 se produce la segunda intervención norteamericana. Esta situación supuso un reto para los intelectuales y escritores de la época, quienes

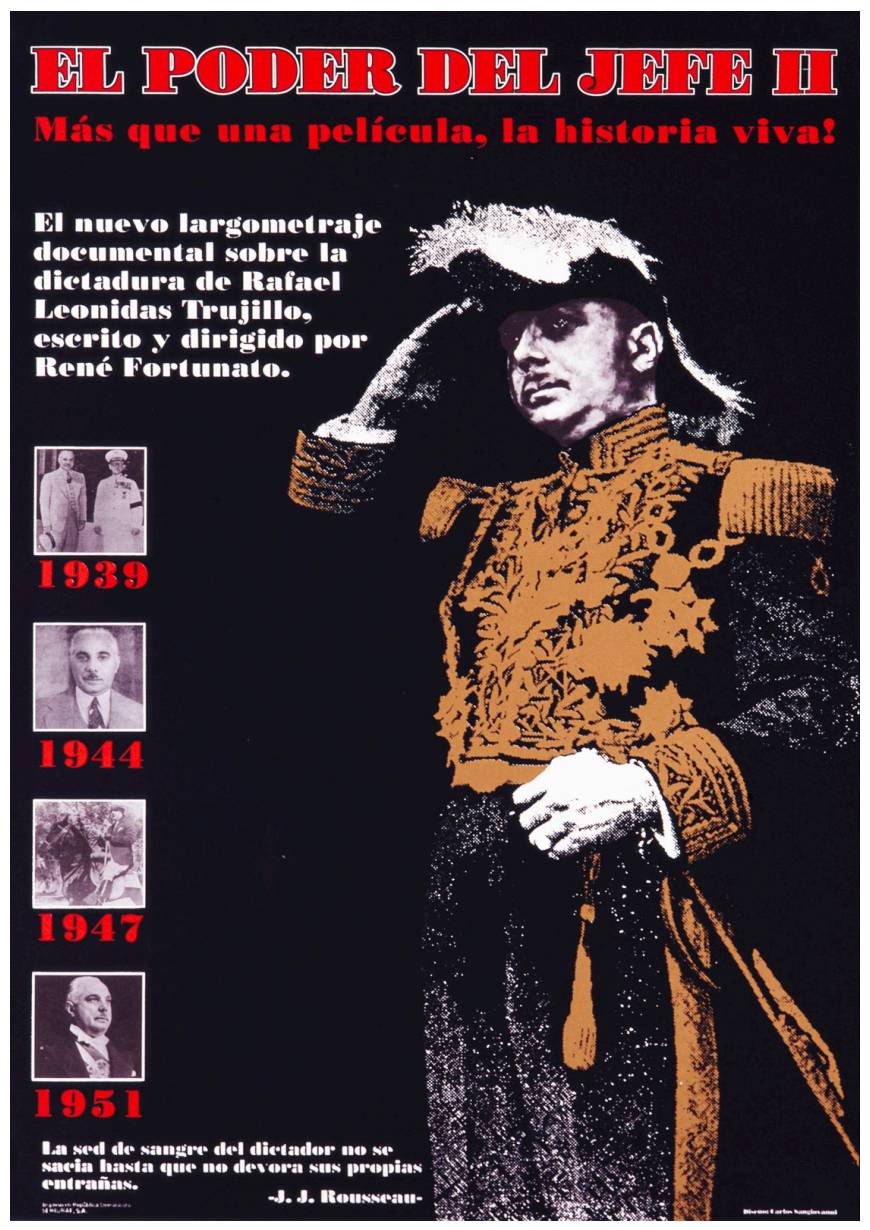

no podían dar la espalda a esta situación político-militar. El cine no estuvo totalmente ajeno a estos temas, como muestra de ello contamos los documentales producidos por Max Pou y Eduardo Palmer en 1967, nombrados en el párrafo anterior.

Trece años más tarde, Agliberto Meléndez estrenó la película, El mundo mágico de Gilberto Hernández Ortega y siete años después estrenó, Pasaje de Ida (1988). Esta última es una de las películas dominicanas más premiadas. Basándose en una historia de la vida real, su trama denuncia los viajes ilegales hacia Estados Unidos. La extorción, el soborno y el sueño americano son muy evidentes en las acciones de los personajes. Fue esa impunidad la que llevó a la muerte de más de una decena de polizontes ilegales que pretendían viajar hacia Estados Unidos de América a principios de la década de 1980 (Fortunato, 2012). 


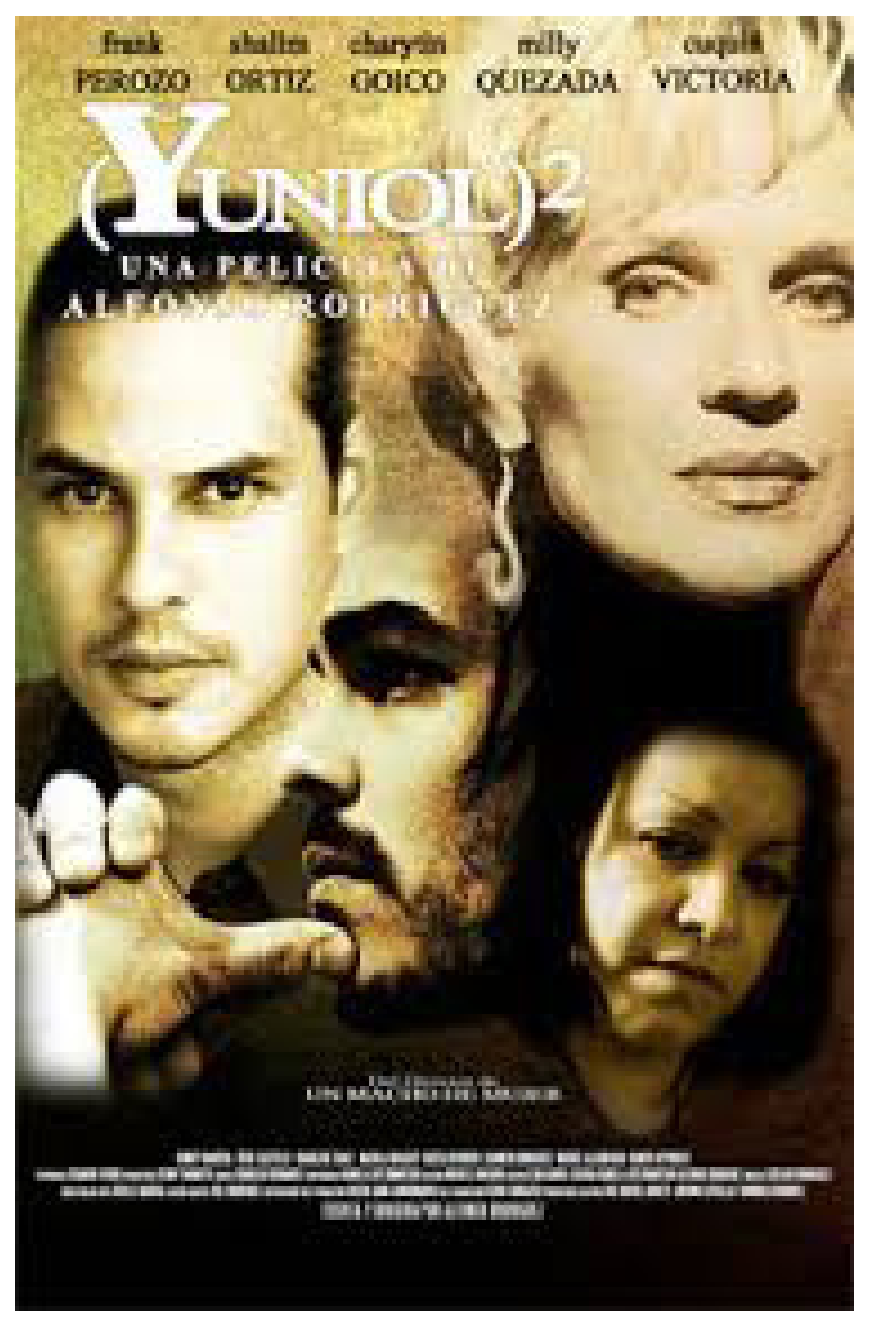

Según cuenta el sacerdote y cronista José Luis Sáez, para la época posterior a la Revolución de abril de 1965 se estrenó el filme Viacrucis, basado en un cuento del profesor Juan Bosch, así como la película Siete dias con el pueblo, sobre un festival de cantantes revolucionarios. Todas estas producciones cinematográficas difundieron discursos alusivos a la situación socioeconómica y política que vivía entonces el país (Sáez, 1982).

La década de los noventa comenzó con la presentación de los documentales: El poder del jefe I (1991), El poder del jefe II (1994) y El poder del jefe III (1996), los tres dirigidos por el cineasta René Fortunato. Mientras Ángel Muñiz se estrenó como cineasta con el éxito taquillero Nueba Yol 1, por fin llegó Balbuena (1995); y Nueba Yol 3: bajo la nueva ley (1997). En el mismo año Pericles Mejía produjo Cuatro hombres y un ataúd (1997).

Un año antes, Radel Villalona y José Romai presentaron Para vivir o morir (1996). En el 1998, los cineastas Josep Medina, Jaime Piña y David Castillo presentaron el drama Buscando un sueño y Jorge Lendeborg estrenó el drama policial Victimas del poder (1998). También René Fortunato publicó

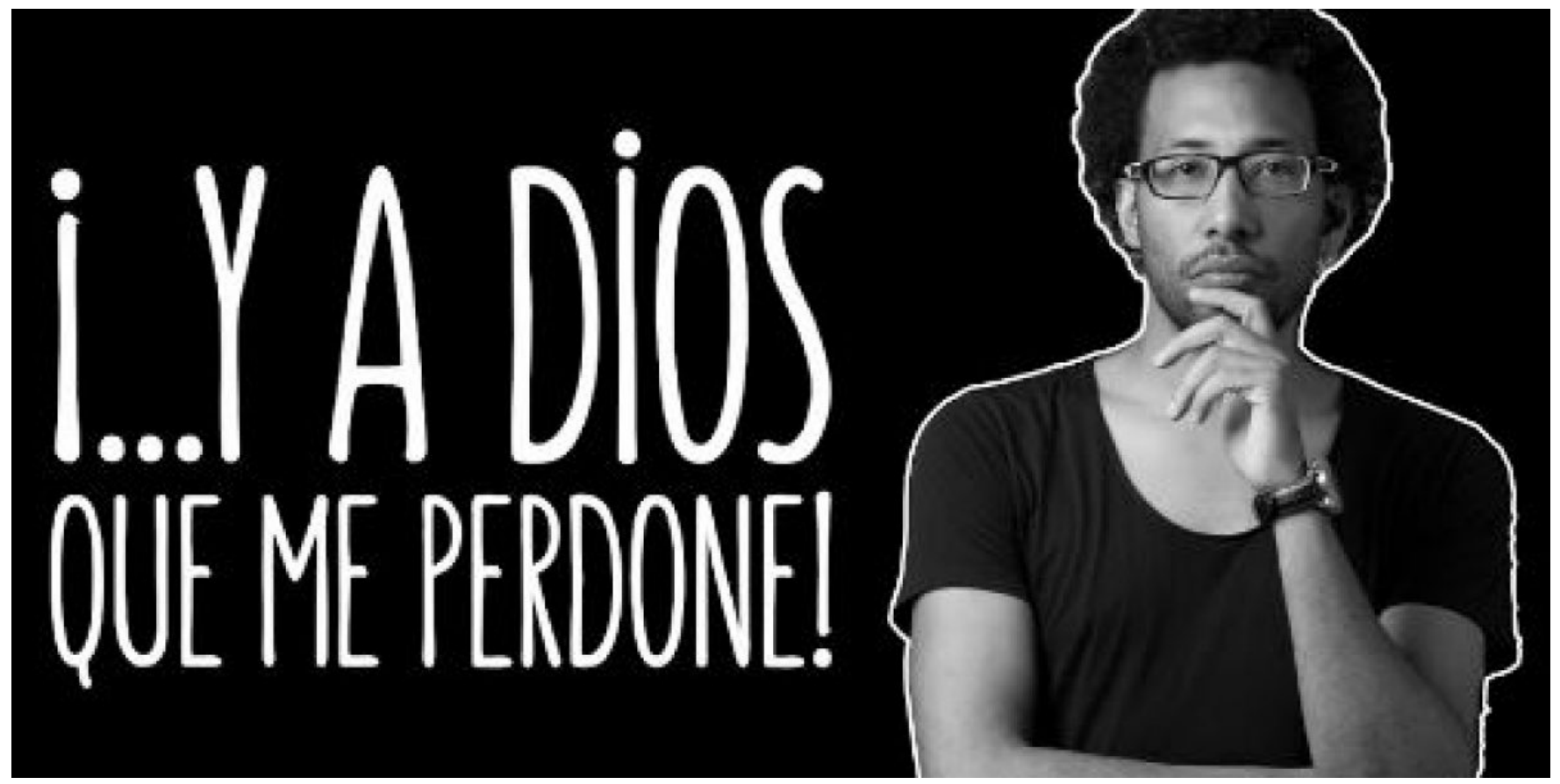

88 | Ciencia y Sociedad 2017; 42(4): 85-90 • Incitaciones 
su quinto largometraje documental, La herencia del Tirano: Balaguery el poder (1998). Asimismo, Nelson Peña presentó el drama El círculo vicioso (1998).

Desde el año 1923 hasta el año 2000, se produjeron 37 películas, incluyendo los primeros conatos de la década de los años veinte a treinta. En la primera década del siglo XXI se incrementó el número y la frecuencia de los estrenos cinematográficos, entre los que cuentan como géneros: el documental, el drama, la comedia, etc. (Lora, 2015). Y desde el año 2000 hasta el 2016 se ha producido un total de 108 películas, más las veinte películas publicadas en el año 2017, lo que equivale a un total de 165. De estas, figuran 97 producciones fichadas y comentadas en el libro Cine dominicano en la mira: catálogo 1963-2014, publicado por la Dirección General de la Feria del Libro, Santo Domingo, en el año 2015. Las fichas de las restantes producciones figuran en diversos medios electrónicos de internet, incluyendo el sitio oficial de la Cinemateca Dominicana.

Hasta este momento, tres han sido los acontecimientos relevantes para el realce del séptimo arte en la República Dominicana: la fundación de la revista Global (2004) de la Fundación Global Democracia y Desarrollo (FUNGLODE), la creación del Festival de Cine (2006) y la aprobación de la Ley General de Cine 108-10 del año 2010. Un cuarto hito está relacionado con la creación de la carrera de cine por universidades nacionales para formar profesionales en este arte reproductor de nuestra cultura (2016).

Uno de los temas que como reto pudiera trabajarse en el cine dominicano, desde nuestra perspectiva, debería estar estrechamente relacionado con los fundamentos ideológicos de las películas con relación a la idiosincrasia del dominicano, lo que implica una mejor estructuración discursiva de los temas contenidos en el desarrollo de la narrativa audiovisual. Esta dimensión podrá tomarse en cuenta a través de un estudio profundo del sujeto dominicano desde una perspectiva histórico-cultural.
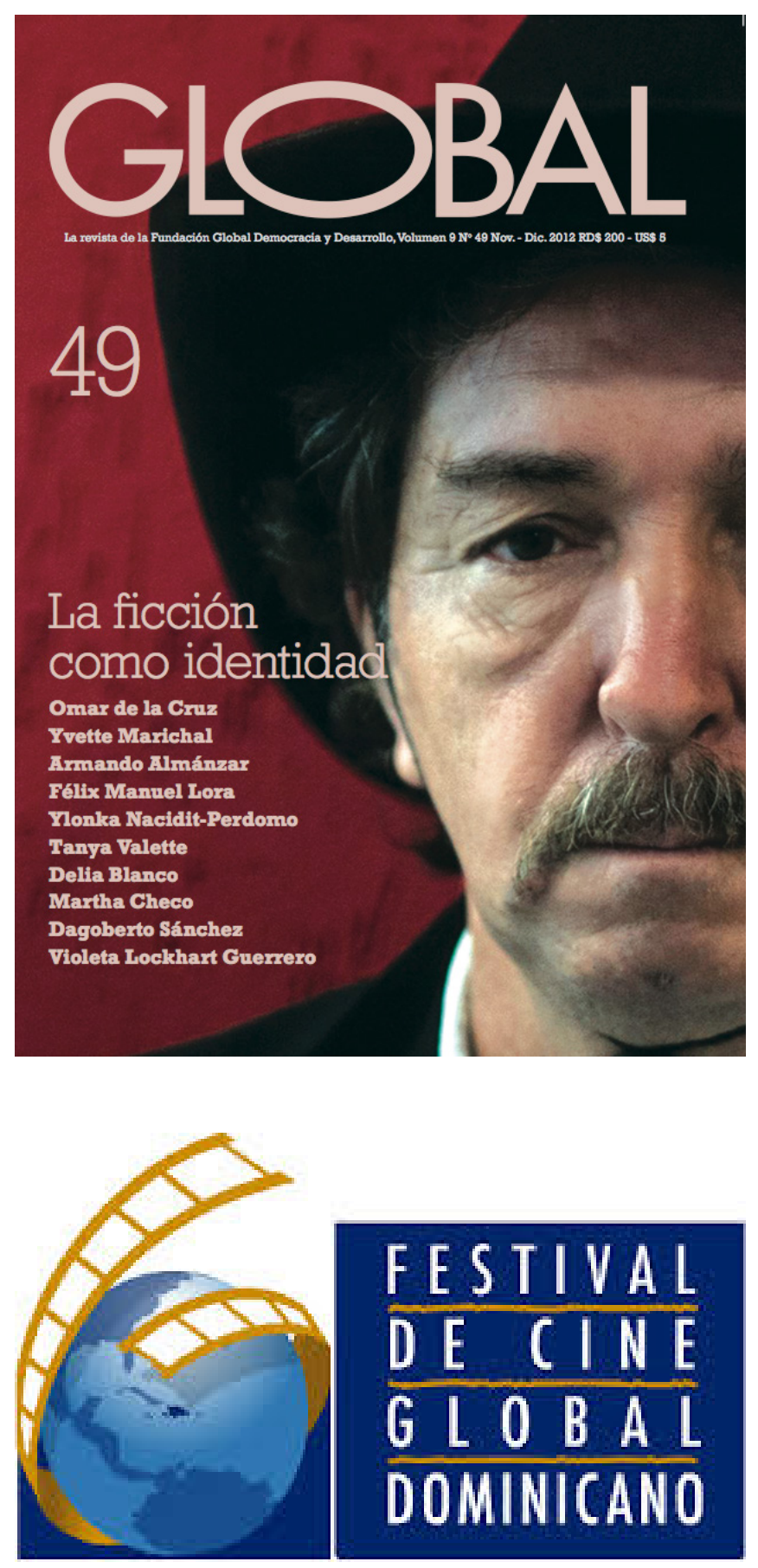

Los numerosos estrenos de películas de los últimos quince ańos no constituyen, ipso facto, conformación de un discurso cinematográfico auténticamente equiparable al fenotipo cultural dominicano. Este es el principal motivo que inspira la investigación que aplico, en la actualidad, a los largometrajes dominicanos de las últimas tres décadas, con la finalidad de realizar un análisis 
crítico del discurso que se difunde utilizando como vehículo el cine, junto a los sustratos ideológicos que contienen cierto poder de enajenación y de liberación, al mismo tiempo, de manera que los resultados puedan servir de insumo a los productores del cine nacional e internacional.

\section{Referencias}

Báez, E. (2017) El cine que la dictadura de Trujillo reguló y prohibió. Periódico el Caribe. Consultado en 17 de abr. de 2017.

Carrasco, W. (2013) La prensa en la dictadura de Trujillo: censura, manipulación y distorsión de la verdad. Periódico HOY, del 29 de mayo de 2013.

Cruz Sánchez, F. (2011) Los medios de comunicación en la República Dominicana. (Cuarta edición). Santo Domingo: Editora del Nuevo Diario.

Fortunato, R. (2012) Escritos sobre cine. Santo Domingo: Taller.

Frías, H. (1985) Pasión de un oficio Moderno. Santo Domingo: Biblioteca Nacional.

Lora, F. (2007) Encuadre de una identidad audiovisual: Evolución y perspectivas en República Dominicana. Santo Domingo: Editorial Valdivia.

Lora, F. (2011) La cinematografía en República Dominicana: evolución y desarrollo del cine de ficción en la RD. Colección "Explorando el cine caribeño" (pp. 357-343).
Lora, F. (2015) Cine dominicano en la mira; Catálogo 1963-2014. Santo Domingo: Editora Taller.

Rudorff, R. (1973). The Belle Epoque: Paris in the Nineties. EP Dutton.

Sáez, J. (1974) Teoría del cine: apuntes sobre el arte de nuestro tiempo. [Motion Pictures]. Santo Domingo: Taller.

Sáez, J. (1982) Historia de un sueño importado. Santo Domingo: Ediciones Siboney.

Sosa, J. (2017) La historia del documental en República Dominicana. Recuperado de Acento. Publicado el 2 de enero de 2017.

\section{Datos de filiación}

Gerardo Roa Ogando es doctor en Filosofía del lenguaje con énfasis en lingüística; catedrático universitario e investigador de Análisis Crítico del Discurso (ACD) en la Facultad de Humanidades de la UASD y profesor del Doctorado en Estudios del Español de la PUCMM. Algunos de sus libros son: La taxonomias del discurso (2016); Estrategias para el desarrollo de la competencia morfosintáctica (2016); Redacción estratégica para el análisis y la producción de discursos académicos (2014); Lingüistica cosmológica (2013), etc. Actualmente realiza un análisis crítico del discurso cinematográfico dominicano.

Correo electrónico: gerardoroaogando@gmail.com 